\title{
Review
}

\section{Stain removal: Ethics and race}

\author{
J. Reid Miller \\ Oxford University Press, Oxford, 2017, 216 pp., \\ ISBN: 9780190280970
}

Contemporary Political Theory (2020) 19, S33-S36. https://doi.org/10.1057/s41296018-00294-9; published online 7 December 2018

In the liberal tradition, the physical markers of the body are morally arbitrary, even if regrettably de facto powerful. Liberals envision a future in which race, gender and physical abilities are irrelevant for justice, and in which the worth of persons is independent of the contingent mark of the body. In a just society, those features are only as important as each of us chooses to make them.

J. Reid Miller quotes Martin Luther King, Jr's liberal 'dream' for his children, that 'one day' they be judged not 'by the color of their skin but by the content of their character' (p. 29), and calls this hope 'a prescriptive fantasy of disembodied ethical knowledge' (p. 29). For King, race may ideally be ethically neutral, but it has become saturated with false meanings that disguise the true worth that is constituted by character. In Stain Removal, Miller undermines this liberal view and explores what he calls the 'logic' of the uncomfortable idea that perhaps 'the body marked by race and other material signifiers could and does attest to ethical qualities of the subject' (p. 29). This would require a metaphysics and epistemology in which experience and knowledge of the world comes already laden with value, in which objects are not evaluatively neutral and only 'stained' by a value that could conceivably be removed to leave the original object intact. Miller explores the suggestion that this is impossible, and that 'the subject exists as valuable only within... affiliative and marked corporeal relations' (p. 34). In this scenario - a nightmare to liberals - race does not corrupt a prior and pure subjectivity, but names a function through which subjectivity comes into being at all, and which then transfers value through inheritable lines. One is not born innocent or free from responsibility, but stained by the responsibilities passed down through inheritance. Rather dramatically, Miller refers throughout to the 'criminal irruption into history' that the black body signifies (e.g. p. 47). The liberal dream, inaugurated by Kant, of a pure and unmarked sovereign subjectivity, is impossible.

In its place, Miller offers a structural account of race in which physically marked subjects are perversely born into structures of responsibilities and evaluations by virtue of those 'stains'; we are 'criminal' by birth and lineage. Race, Miller says,

(c) 2018 Springer Nature Limited. 1470-8914 Contemporary Political Theory Vol. 19, S1, S33-S36 
refers to 'a historical instantiation of an irreducible, necessary, and mythic logic that fashions a synthetic arrangement of subjectivity, materiality, and value' ( $p$. 34). Race is not the only means through which responsibility and value come into being, and in fact the book is not essentially about race at all. Insofar as race has been the marker historically most associated with negative significance, its power is obvious, but Miller's point is that a 'semiotics of value' could be conducted through gender, age, or a variety of physical characteristics that 'conscript' subjects into ethically problematic lineages (p. 26).

Stain Removal attempts to make sense of how 'criminal responsibility' could be both assigned to each person as individually merited and at the same time inherited. I think that this tricky task is attempted through the exploration of a number of substantial claims. One is that subjectivity is necessarily embodied; a second is that experience and knowledge of the world is only possible through 'a semiotics of value' (p. 119) - ontology is always 'stained' by value. A further, related, claim is that the identification and nature of individual discrete acts 'remains indissociable from the evaluatively embodied context of its performance' (p. 107). These claims make the book an exploration of ethics and race, rather than the ethics of race; the latter approach, Miller thinks, assumes that there is a neutral object - a body - that is then the appropriate object of ethical evaluation and racial classification, rather than the raced body being already experienced and brought into being evaluatively, or race being from the start ethically stained. Ethics, for Miller, explores 'the conditions for the emergence and existence of value' (p. 26).

These claims are made in perhaps new terms but in some form or another they are not unfamiliar. The view that the world and subjects are not ontologically neutral has been pressed on us by scholars of different persuasions, and the factvalue distinction has not been rigid for a long time. But Miller presents his claims as necessary, although their precise content is not clear. I am not sure how Stain Removal establishes them - or, indeed, whether they are supposed to be established, or simply raised as possibilities for reflection. This fascinated bemusement is a familiar feeling by the end of the book.

The most controversial - and elusive - claim is that structural concepts like race, which, contrary to prevailing liberal notions, tie responsibility and moral worth to inheritable and contingent features, are paradoxically necessary for notions of individual moral responsibility, and that ethical descent must accompany genealogical descent. Somehow, individual and inherited responsibility dovetail through the work of race. Miller claims that

... myths about why bodies resonate different values, expressed in our age by the concept 'race', are what makes notions like 'individual moral responsibility' conceivable. It asserts, in other words, that the idea of ethical accountability as restricted to traits wittingly developed rather than 'accidentally endowed'... could come into modern existence only in tandem 
with a countervailing notion like race in which inheritable and accidental endowments are the active conduits of comparative ethical worth. The book thus makes the argument... that while the manner in which 'race' manifests is specific to modernity, its structural function is not' (p. 25).

That merited responsibility could 'come into existence' only along with a notion of inherited worth is a hefty claim indeed and is apparently explained in the core chapters 3 and 4 by the premodern notion of a 'curse' through which 'criminality' is inherited - the elliptical biblical story of Noah's curse of Ham and his descendants is the central text here. Through an unnamed 'crime', value enters the world and makes possible subjectivity and agency. Ham is responsible for what he illicitly came to know of his father, and his descendants inherit their father's responsibility. While the logic of the curse is no longer available to us, Miller suggests in chapter 5 that modern accounts of subjectivity - like those of Althusser's and Sartre's - take up and continue the notion of a criminal embodied subjectivity.

How are we to read Stain Removal, and what are we to do with its claims? It is difficult to see quite how Miller supports them. More fundamentally, are they claims - or imaginings? Which ought we to accept and which merely to entertain? The book is dense, elusive and allusive; inaccessible, I suspect, to those not familiar with Miller's structural and poststructural framework. The exploration of the 'curse', which enables normativity and makes responsibility for the ethical markings of the body inheritable, works through brilliant, possibly perverse, readings of a mysterious passage from Genesis, and draws variously on the myth of Oedipus, St. Augustine, Philo, and a reading of Kant's anthropological studies of race. Fascinating as these investigations are, they raise many questions beyond a call for clarity on precise content and scope: Why, for instance, should the obscure and ancient 'Hamitic event' guide how we understand race? How can it support a structural reading of race (or any physical markers?) as necessary for subjectivity? Why go along with an ancient 'logic' that attempts to explain how worth and guilt may be inherited, not solely earned? If such myths have influenced us - if they are myths - why not discard them? Are we, indeed, asked to discard them, or to understand them? How does race operate structurally in comparison to other physical markers?

Stain Removal does not make prescriptions about what to do about race or racism. Miller warns readers of his 'criminal intentions' in the introduction (p. 25): he will not provide political and ethical prescriptions for how to bring about the 'end of race as the end of racial prejudice, a.k.a., freedom from race' (p. 25). He dashes the hopes of those who cling to the liberal dream of a just state in which we do not inherit bodily the sins of our fathers, or the curses or blessings of a capricious God. He offers (through James Baldwin and Langston Hughes) only the ongoing inheritance of a continually re-valued worth, and even this is not innocent:

(c) 2018 Springer Nature Limited. 1470-8914 Contemporary Political Theory Vol. 19, S1, S33-S36 S35 
Before one 'loudly declares an unwillingness to speak the criminal secrets of one's ethical heritage, and thus to pass the curse down the line' (p. 171), one should remember that what is a blessing today could, by arbitrary fortune, be a curse tomorrow. But what is one to do with that dark prediction? Miller's intriguing book offers us no solutions. If we are destined to remain entangled in the logic of an inherited curse, there is no hope for racial - or any other - justice.

Samantha Vice

University of the Witwatersrand, Johannesburg 2000, South Africa samantha.vice@wits.ac.za 